\title{
Online diaries: Reflections on trust, privacy, and exhibitionism
}

\author{
Paul B. de Laat \\ Faculty of Philosophy, University of Groningen, Oude Boteringestraat 52, 9712 GL Groningen, The Netherlands \\ E-mail: P.B.de.Laat@rug.nl
}

\begin{abstract}
Trust between transaction partners in cyberspace has come to be considered a distinct possibility. In this article the focus is on the conditions for its creation by way of assuming, not inferring trust. After a survey of its development over the years (in the writings of authors like Luhmann, Baier, Gambetta, and Pettit), this mechanism of trust is explored in a study of personal journal blogs. After a brief presentation of some technicalities of blogging and authors' motives for writing their diaries, I try to answer the question, 'Why do the overwhelming majority of web diarists dare to expose the intimate details of their lives to the world at large?' It is argued that the mechanism of assuming trust is at play: authors simply assume that future visitors to their blog will be sympathetic readers, worthy of their intimacies. This assumption then may create a self-fulfilling cycle of mutual admiration. Thereupon, this phenomenon of blogging about one's intimacies is linked to Calvert's theory of 'mediated voyeurism' and Mathiesen's notion of 'synopticism'. It is to be interpreted as a form of 'empowering exhibitionism' that reaffirms subjectivity. Various types of 'synopticon' are distinguished, each drawing the line between public and private differently. In the most 'radical' synopticon blogging proceeds in total transparency and the concept of privacy is declared obsolete; the societal gaze of surveillance is proudly returned and nullified. Finally it is shown that, in practice, these conceptions of blogging are put to a severe test, while authors often have to cope with known people from 'real life' complaining, and with 'trolling' strangers.
\end{abstract}

Key words: blogs, diaries, exhibitionism, panopticism, privacy, surveillance, synopticism, trust, voyeurism

\section{Introduction}

My depression is atypical, which means that I oversleep and I overeat and my motivation is the pits. I've lost interest in everything I used to adore; I can't even concentrate on watching television for more than 5 minutes! I've become extremely sensitive and over-emotional and I've isolated myself [from] all of my friends. Furthermore, my self esteem is as low as it can be. I've gained thirty-five pounds, inducing a panic that led me to disordered eating. I suffer from chronic pain and headaches. [...] I'm either sleeping or eating or sitting in the tub with the shower water running and crying my eyes out.

(Avernales, a 21 year old woman suffering from depression since she was 18 , in the profile on her online diary entitled 'Take back my life: It's NOW or NEVER', started on 22 March 2007; retrieved May 2007 from http://avernales.livejournal.com/ profile; some time later, this journal was 'deleted and purged')
In the last decade many scholars have come to appreciate the very social character of virtual relationships on the Internet. In particular, trust between transaction partners in cyberspace is not to be ruled out. The argument about trust concerns both its existence and its genesis. On the one hand, seemingly against all the odds, relations characterized by trust may be observed between virtual partners. On the other, such trust may be created in an unorthodox fashion: trust is simply assumed, not inferred from available evidence. It is upon this mechanism of creation that this article focuses (in the first part to follow below). More particularly, it is shown that assuming trust is the basic mode of operation in online diaries. Their revelation of intimacies is predicated on the assumption that their readers have no ill intentions and will respect their confidences.

\section{Assuming trust: A survey}

A brief survey of how this unorthodox argument about the genesis of trust has developed over the 
years may be useful. The following lines of research may be distinguished - all of them originating in pre-Internet times and thus relating to 'real life' only. In the 1980s and 1990s the concept of trust experienced a mini-revival in several disciplines. Philosophers, economists and social scientists started to pay attention to the concept of trust once again. Niklas Luhmann was arguably one of the first to do so (Luhmann 1968), although his work was only taken up much later. Subsequently, important analyses were contributed by Annette Baier (1986; 1992), Diego Gambetta (1988), and Philip Pettit (1995). Their concept of trust is roughly comparable: reliance on the competence and good intentions of other(s) in situations characterized by vulnerability and high risk. More particularly, all these authors pondered the possibilities of trust relations starting not by inference, but by simple assumption. An act of trust in this vein was interpreted as an investment that it was hoped would pay off. By way of an introduction to the issue, let us focus on Gambetta's analysis. Echoing Luhmann's conception of Vertrauen in Vertrauen (Luhmann 1968, p. 85 ff.), Gambetta formulated the question: 'Can we trust trust?' He argued that if we do not test our trust of the other by 'acting as if one trusted', we shall never be able to discover whether the other is to be trusted or not. By trusting nevertheless, we encourage the other to commit himself to the relationship. Therefore, "the concession of trust $[\ldots]$ can generate the very behaviour which might logically seem to be its precondition' (all quotations from Gambetta 1988, p. 234).

Following this line of inquiry, Debra Meyerson, Karl Weick, and Roderick Kramer conducted a survey of the literature on temporary groups that come together in real life to perform a collective task (Meyerson et al. 1996). Why do these 'temporary systems act as if trust were present', while 'their histories seem to preclude its development' (Meyerson et al. 1996, p. 167)? They tentatively concluded that in such groups either trust was assumed at the outset and acted upon, or trust was not forthcoming at all. The phenomenon was aptly dubbed 'swift trust'. The dynamics of tight interdependencies between participants, high risks, and high time pressure were supposed to account for it. Shortly after, Sirkka Jarvenpaa and Dorothy Leidner transferred this research agenda into cyberspace (Jarvenpaa and Leidner 1999). They explored whether trust could develop between members of virtual work teams that did not have any face-to-face interaction. Studying teams of students in cyberspace, unknown to each other, they found that trust did indeed develop in half of them, and it was only by assuming trust that the genesis of trust had a chance. So the phenomenon of trusting trust - without apparent reason - had now also been identified in virtual life. From this study onwards, several authors have continued to analyse and comment on this very phenomenon. Patricia Wallace tracks the development of trust across a variety of virtual settings (Wallace 1999, in particular p. 86), and John Weckert analyses the creation of online trust by choosing to act as if one sees others as trustworthy (Weckert 2005, p. 113).

This line of research, however, can be strengthened and specified more clearly by returning to the authors involved in the mini-revival of research on trust. On the one hand, Baier and Pettit alert us to the fact that, when specific clues about the other(s) are lacking, people do not rely on trust without any considerations at all. They usually estimate, in a more general sense, whether or not the obtaining 'climate of trust' is conducive to trust moves (cf. Baier 1992; Pettit 1995). On the other hand, the mechanism underlying an assumption of trust - if any - can be clarified. Luhmann analyses the act of trusting as a risky investment (Vorleistung) that has normative consequences. While it is incurred voluntarily, it is considered a merit and commands esteem (Achtung) from the other ('supererogatorische Leistung'). As a consequence, a normative claim upon the other develops to reply in kind (Luhmann 1968, p. 55). Luhmann refers to the analogy of a gift: a gift, whether small or large, invites a gift in return (Luhmann 1968, p. 56). And so it is for an act of trust (which may, of course, involve the giving of presents). Therefore, one may have Vertrauen in Vertrauen and just go ahead (Luhmann 1968, p. 91).

Some time later, without explicitly taking Luhmann into account (!), Philip Pettit developed his own theory about two mechanisms of trust (Pettit 1995). Trust - in the sense of 'dynamic, interactive, trusting reliance involving high risk' - will usually be based on a belief that the other is trustworthy ('primary trust'). Another, more subtle mechanism of trust ('secondary trust') is based on the belief that the other cherishes my esteem and will therefore reply to an act of trust in kind ('trust-responsiveness'). It is a gesture that motivates the other to perform well in return. Pettit analyses the act of trust as a risky investment that should pay off as long as the trustee does not want to forfeit the chance to reap the esteem of the trustor.

As can be seen, both Luhmann and Pettit put different emphases, but refer to the self-same mechanism of assuming, not inferring trust. One may have trust in the mechanism of trusting others, without any concrete evidence of trustworthiness being available. 
Central to the mechanism is the exchange of esteem. Taken together, I would argue that the issue of trusting trust (Gambetta, Pettit), Vertrauen in Vertrauen (Luhmann), or reliance on trust (which Baier claims to be the more accurate wording; Baier 1992 , p. 138) has been squarely put on the research agenda. A wide range of authors from different backgrounds seem to converge on this.

In a recent article (de Laat 2005) I explored whether this mechanism of assuming trust had any bearing on relationships in cyberspace. While in Pettit (2004) it was argued that it was impossible for virtual trust to develop and it was bound to remain a (dangerous) illusion, I came to the opposite conclusion. In a wide range of contexts, trust does empirically seem to obtain between pure virtuals. Moreover, while primary trust often does not suffice as the whole explanation, I argued that secondary trust does seem to play a vital role in its genesis. In order to arrive at this conclusion I explored market transactions, task groups, and non-task groups focusing on recreation and group support. The technological means employed by these groups were mailings lists and websites. Recently, a new technological mode of communication has emerged: web logs, or blogs for short. Insofar as these are used to express personal and intimate matters of one's life (online diaries), they would seem to be a useful area to perform a detailed study of the phenomenon of assuming trust in cyberspace.

\section{Blogs}

Routinely, blogs are defined as websites on which dated entries are frequently uploaded and presented in reverse chronological order. Comments about any subject, of any length, can be presented to the world in this format. When, in 1999, technology had evolved sufficiently and blogs became available as hosted services (provided by Blogger, LiveJournal, and the like), their numbers rose sharply. Currently, millions of blogs can be found in cyberspace. To varying degrees, blogs may be equipped with specific technical features (cf. Herring et al. 2004). Archives may be set up containing older entries than the ones displayed; they are mostly searchable, too. 'Permalinks' allow visitors to link directly to any individual blogpost. A list of links to other bloggers ('blog roll') may be presented. Badges signal affiliations of interest. Relations of friendship are usually dis- played in a two-way fashion: bloggers may list blogs of those they consider their friends, as well as the blogs of those who consider them to be their friend (without reciprocity implied). Sometimes (though not often; Herring et al. 2004, note 14), comments are allowed - even invited - on individual posts, or on the blog as a whole only. 'Trackbacks' alert blogger A that, on blog B, (s)he is being commented on.

Bloggers often have technological options available to manage their privacy (cf. Kozlov 2004). With many hosts, one may install restricted circles of participants. With Vox (SixApart), for example, apart from blogging in total secrecy (cf. classical diary) or for the world at large, one can communicate within a circle of relatives, and a circle of friends. Accepted members may be granted reading rights only, or writing rights as well. Moreover, blog owners may 'manage' incoming comments in order to keep interactions smooth (comments can be screened from view, be temporarily frozen, or even deleted; anonymous comments can be turned away).

What are the authors blogging about? According to Blood (2000), it all started with filter style blogs that made a personal selection of interesting sites available to readers. A kind of alternative public sphere was being developed. Thereafter, personal journal blogs started to appear, in which authors chronicle their lives. Such diaries are by now the main type of blog, at least in the US (about 70\%; cf. statistics in Herring et al. 2004). Other types are klogs (for sharing of knowledge) and blogs for artistic purposes (Herring et al. 2004). At the same time it has been found that, available options to install more intimate circles notwithstanding, the overwhelming majority of blogs are publicly accessible. Bloggers blog for the world at large. Moreover, bloggers' identities are apparent most of the time, while they provide a name or a pseudonym, as well as many personal details (Herring et al. 2004; Schmidt 2006, p. 78).

It is upon these personal, publicly available online diaries that I focus from now on. The analysis that follows is based on the few existing academic studies of diaristic blogs, and on a cursory reading of a random sample of online diaries themselves. Moreover, my analysis purports to apply mainly to such blogs in countries from Western Europe and North America. For one thing, most blogs originate there (at least until recently). For another, the cul- 
tural phenomena involved - of trust, privacy, and intimacy - are bound to have different meanings and different implications elsewhere. ${ }^{1}$

\section{Online diaries}

Online diaries usually chronicle intimacies of both the soul and the flesh (cf. the opening quotation above, from one diary out of many). Their mostly solitary authors enter upon a journey of self-discovery and intellectual self-reliance (Blood 2000). Why do bloggers engage in such adventures? What are they expecting to gain from their public efforts? Although research is scarce on this recent phenomenon, most accounts converge on the following motives (cf. Miller and Sheperd 2004, leaning heavily on Calvert 2000; Schmidt 2006, Chap. 4). On the one hand, diaries involve a personal project centred on the self: the blog is a means of self-clarification and self-validation. By sustained writing about the events, thoughts, and emotions of one's life, one is able to discover and develop who one 'is'. On the other hand, there is a need to get to know others, to develop a community of sympathizers. Otherwise there would be no point in publishing one's diary in the open. Moreover, these community relationships can be consciously 'managed' with the options for selective linking and commenting mentioned above. In this way, bloggers position themselves in the bloggers' community (Blood 2000).

It can safely be assumed that online diarists are moved by a combination of both motives, with some tending towards the blog as a personal project, while others incline towards the blog as a social project. Furthermore, the two motives are intimately connected: reflections upon the self are the entry ticket to a potential new community, while the feedback from the community may afford a better grip on leading

\footnotetext{
1 Regarding the issue of quoting online personal journals, my position is the following. Some have argued that publicly accessible records of electronic communities may not be quoted for academic purposes without permission, but only with consent (before the content has actually been produced) from the author(s) involved (for a review of the discussion see Bakardjieva and Feenberg 2000). I do not think, however, that this 'non-alienation principle' applies to the diaristic entries cited in this article. For one thing, the web diaries involved are fully public at the time of writing, or were so during their lifetime, without any technical restrictions on entry. For another, many of the blogs used have been incorporated in public archives, which were set up precisely for the sake of research. I therefore felt free to cite without permission, and include the authors' names as well.
}

one's own personal life. As the French psychology tradition phrases it so aptly (cf. Serfaty 2004, p. 92): by externalizing one's intimate life through selfdramatization and/or theatricalization, one may be more able to grasp and re-internalize elements of one's inner life. 'Extimacy' is in play (intimacy turned inside out), a term coined by Jacques Lacan and further developed by others like Jacques-Alain Miller.

The ongoing dialectic is nicely worded by blogger Jack in his entry 'Why I Blog' from 7 December 2005:

I am part of a community of bloggers, a part of the overall blogosphere and at the same time I am also part of many other groups within the blogosphere. I am able to reach out and click someone. I can see that there are others who are facing the same challenges I face or have already overcome them. I take strength in their words and I offer my own.

Here at the keyboard I commune with others and speak about my life. I offer my insecurities and my beliefs. I open my mind and try to learn about the world around me. I am always searching and seeking for new things to learn.

(retrieved from http://wwwjackbenimble.blogspot. com/2005/12/why-i-blog.html)

Or as Lunesse, who started a diary in 1996, expressed it:

I learned tons about others, of course. Lives I never will live myself, thoughts I wouldn't have come across on my own. I have learned how to better process and work through some things in my life as a result of reading how others went through similar things.

I also learned about myself, how open I really am, and what about. I learned what it is like to take on the responsibility of making your own life public, and that of those around you, and how to deal with doing that in a manner that is fair.

(interview from the year 2000; retrieved from http://www.diaryhistoryproject.com/recollections/ 1996_11_20.html)

\section{Extimacy: Towards an explanation}

So diarists are typically exposing many details of their inner lives. Their motives seem clear enough. But why do they take the risk of exposing themselves so publicly to the world at large? Why this gamble of extimacy on the scale of the Internet? Notice that bloggers can play it safe if they prefer to do so. Common sense would suggest that intimacies are only to be revealed to 'insiders' who have already 
shown themselves to be trustworthy ('primary trust'). This would suggest differentiating the level of intimacy around several circles: intimate blogging for insider circles (like relatives, or friends), more cautious blogging for the world at large. Technically, such arrangements can be implemented now (cf. above).

The astonishing reality, contrary to expectations, is that most blogs are wholly public. One may argue that ignorance about available privacy options might be involved. Another feasible explanation is that would-be bloggers have studied the blogging phenomenon for a while, and come to the conclusion that confidence in public blogging is warranted (in the Luhmannian sense: danger is perceived to be involved, but not risk). It might also be supposed that many diarists just unwittingly follow the example of bloggers who started a diary before them.

Nevertheless, many bloggers are aware of the risks of being in fully 'open' cyberspace. Relatives or friends may start a quarrel about intimacies revealed, and anonymous 'trolls' may start harassing one's blog. Why is it, then, that online diarists dare entrust the intimacies of their daily lives to the world out there? Considering the distinction between primary and secondary trust as coined by Pettit (1995), which mechanism of trust is in play? This question seems to have an easy answer. Diarists have no indications whatsoever about the trustworthiness of potential visitors to their site. The more usual mechanism of inferring trust cannot apply. I would argue, therefore, that public blogging, if undertaken in consciousness of the risks, is to be interpreted as a case of secondary trust: authors simply assume that at least some others out there will be moved by their display of intimacies and react accordingly.

This is not to say that diarists have no clues whatsoever at their disposal when assuming trust. In a general sense they can make an informed estimate of the climate of trust prevailing in the blogging circles they intend to become part of (cf. Baier 1992; Pettit 1995). They may have read other blogs, and monitored the comments on them -if any - for a while. Moreover, they may reflect on their own reactions to reading blogs by other authors. Based on such observations, diarists may with some confidence conclude whether or not specific blogging circles seem hospitable enough - in a general sense - to tell all about themselves.

Pettit was drawn into his analysis of 'trusting' situations that revolve around assuming trust, while he believes that it has normative implications that have been overlooked. He points in particular to the creativity and ubiquity of trust in civil society (Pettit 1995, Sect. IV). That is, trust may develop ex nihilo in a great many social situations. The examples he mentions and elaborates are the taxi passenger who trusts the driver to get her to her destination by the shortest possible route, and the new resident handing over the house keys to his neighbours, trusting that they will take care of the house. These social situations involve relations between two parties meeting face-to-face.

I would argue that online diaries represent a quite different - and more complicated - trusting situation. On the one hand, blogging would seem to be a less frightening affair. An author entrusts his/her intimacies to the world at large, not as a one-to-one but a one-to-many relationship. Moreover, these spectators are invisible and anonymous. In that sense, blogging amounts to a generalized act of trust (addressing not a specific stranger but a non-specific, invisible, multitude of strangers). Engaging in such an act, sitting safely behind one's computer screen, would seem to generate less angst than the situations that Pettit discussed. On the other hand, blogging online also has more frightening aspects in terms of trust. Blogging is not a one-time display of trust but a continuing one: a diary is an effort to produce entries in a continuous fashion (most blogs are updated every day; Herring et al. 2004). Entries, moreover, are recorded and archived: intimacies remain visible. So blogging amounts to trusting the world out there day after day, on a fully retrievable basis. The trusting situation is more enduring than in Pettit's cases.

With these comparative aspects in mind, we may try to answer the question: Why does this arrangement apparently work - most of the time? Why are bloggers not ridiculed and taken advantage of - most of the time? Part of the answer, I would argue, can be found in the technological features of blogging. As discussed above, trusting transforms into a generalized act of trust. This not only makes life easier on the part of the sender - it also does so on the part of the receiver. An act of generalized trust is much easier to handle than the classical face-to-face approach. Cyber-visitors can decide, unobserved while being invisible behind their screens, whether or not to take up the invitation.

On the one hand, they may like and admire the prose, identify with its author, and turn to a daily reading of the entries. Possibly they may also return some comments of their own. If visitors provide feedback, this might be out of courtesy or respect. They express their affinity in return. Additionally - or solely - they may be motivated by the prospect of earning admiration from its author in return (trust-responsiveness). On the other hand, people stumbling on a blog may also, of course, react otherwise. The blog's entries may not particularly appeal to them, or even appal them. In those cases, abuse may seem a likely 
possibility. However, I would argue that they are more likely just to ignore the blog's existence. Two circumstances would seem to mitigate the danger of abuse. For one thing, visitors may simply be civilized people, not inclined to abuse their fellow-man. For another, embarrassment or disgust may only arise if visitors have at least glanced through some entries of the blog. By that very fact they would seem to be implicated in the matter. I would argue, though in a more speculative vein, that as a result, if they harbour any self-respect, abuse on their part is held at bay inasmuch as it would make them feel awkward and ashamed. Remarkably, trust-responsiveness (revolving around self-esteem) may keep abuse in check (cf. also Pettit 1995, note 19). So the normative power of trust (cf. Luhmann's terminology) supposedly is twofold here. On the one hand, visitors who are 'turned on' by the diary may feel compelled to comment on it; on the other, visitors who are 'turned off' by the blog involved may at any rate feel obliged to refrain from opportunism.

This mechanism might also be phrased more loosely as follows. An author imagines that at least some people will feel sympathy for her blog entries, while the remaining visitors, after a cursory glance, will simply ignore her. Ill-will and associated 'trolling' are presumed to be out of the question. At this point it might be useful to refer to a similar analysis, provided by Nicola Döring, who reviewed the research about the design of personal home pages (Döring 2002). She observes that their authors - just like our online diarists - update frequently (at least monthly) and are involved in both a personal and a social project. An overwhelming majority seem to present authentic selves. She concludes that in revealing private details about themselves, authors imagine 'attentive and well-disposed' others out there (Döring 2002, Reception of ...). This fantasy apparently pays off: most comments they actually receive are supportive and full of respect. Döring does not specify if and how the two phenomena might be connected. I would of course speculate that the connection is causal: precisely by imagining (i.e., assuming) a supportive audience, at least part of that audience effectively becomes so. By assuming others to be worthy of one's intimacies, at least a number of them will indeed become one's intimate correspondents. A self-reinforcing cycle of mutual admiration is created.

As one of many, Jesse Chan-Norris, blogging since 1997, aptly expresses his experiencing this cycle as follows:

The notion of the anonymous, or semi-autonomous, audience is what, I think, drew me to the online journal in the first place. And to finally know that people out there actually did read what I had to say (and to know this from actual words and not from access logs or something equally cold and impersonal) was wonderful. Plus, there is nothing quite like mutual admiration to really say "Ok, what you are doing is good and you should keep on doing it."

(interview from 2000; retrieved from http://www. diaryhistoryproject.com/recollections/1997_01_09. html)

Nevertheless, this analysis of technological features of computer-mediated communication facilitating the trend towards exposure and gambling on trust seems to be only part of the answer. At the same time, more general cultural developments seem to be involved. In the footsteps of Mathiesen (1997), Calvert (2000), Miller and Sheperd (2004), and Koskela (2004) I argue in the second part of this article below, that the culture of 'mediated exhibitionism' and 'mediated voyeurism' that has been evolving during the last decades plays a central role. This media(ted) culture, also denoted as 'synopticism', occupies a pivotal position in my argument. On the one hand, it can be interpreted as a (perverse) reaction to the gradual erosion of privacy in the 20th century. On the other, it is provoking a countermovement against its alienating and exploitative features that aims to turn exhibitionism into a more authentic, empowering force. Diaristic blogging can be interpreted as part of such 'empowering exhibitionism'. Received notions of the distinction between public and private, of privacy, are challenged in the process. Several degrees of empowerment are distinguished, as evidenced in the design of the diaristic synopticon. It is shown, finally, that living up to one's conceptions in practice may be a hard task indeed.

\section{Empowering exhibitionism}

Clay Calvert is to be credited with coining the term mediated voyeurism: the 'consumption of revealing images of and information about others' apparently real and unguarded lives' (Calvert 2000, p. 2). For decades now, several kinds of voyeurism have become part and parcel of the programs broadcast on $\mathrm{TV}$. It has become normal to watch video images of people being beaten up by the police ('video vérité'). From Survivor and Big Brother to Jerry Springer shows, we enjoy watching people in their apparently genuine moments of anguish. With the Internet, the trend is continuing; 'girl-cam sites' are a case in point. Obviously, mediated voyeurism needs mediated 
exhibitionism: people - at least some of them - must be willing to put themselves on show.

What are the origins of this voyeurist culture? Calvert makes an interesting connection with the erosion of privacy, characteristic of the late 20th century. We live in a society where by now 'we expect to be watched, and concomitantly, we expect to be able to watch others' (Calvert 2000, p. 94). So he argues that while our personal privacy is no more, as a corollary we no longer feel obliged to respect the privacy of others. While we feel transparent, we declare the right to peer into the lives of others. The Big Brother shows of today are directly related to the Big Brother (or Panopticon) tendencies of our information society at large.

A similar type of analysis has been provided by Thomas Mathiesen. While actually borrowing from Frank Henriksen, he proposed the term synopticism for the phenomenon that through the modern mass media 'the many have been enabled to see the few - to see the VIPs, the reporters, the stars, almost a new class in the public sphere' (Mathiesen 1997, p. 219). Next to panopticism, he argued, the phenomenon of synopticism has developed, together constituting a 'viewer society'. Both mechanisms of control have grown at increasing rates and in intimate interaction over the last two centuries (Mathiesen 1997, pp. 218-225). Voyeurism-cum-exhibitionism may be considered roughly equivalent to synopticism thus defined.

On the basis of both analyses we are able to understand the phenomenon of online diaristic blogging as a cultural life form. These web diarists are exhibitionists exposing intimate details of their lives on purpose; correspondingly, their readers are engaged in voyeurism of a kind. However, is this exhibitionism and voyeurism just a technological extension of what was happening before? Is it to be considered more of the same? According to Carolyn Miller and Dawn Sheperd, who conducted a genre analysis of blogs (Miller and Sheperd 2004), the Internet in general offers ever-increasing possibilities for exposure in public: 'On personal home pages and message boards, in chatrooms and on listservs, and most especially on blogs, people are sharing unprecedented amounts of personal information with total strangers.' So blogging is just the most recent addition to the Internet-enabled repertoire of exposure. With this observation I have no disagreement.

In addition, however, these authors draw a continuous line from the (older) categories of exhibitionism as discussed by Calvert to the (more recent) Internet-related forms of exhibitionism (and Calvert does precisely the same; Calvert 2000). I would argue, on the contrary, that there is quite a difference between them. Blogs, home pages and even webcam sites do differ from Big Brother and Jerry Springer shows. Mediation is, of course, ever present. In the older cases, however, the exposure is managed and staged by commercial media engaged in their production. The exhibitionists involved allow themselves to be exploited. In the Internet cases, the individuals concerned try to express themselves directly: selfrepresentation through their own medium is at stake. This is a potentially liberating exercise. It is an effort to turn commercialized, exploitative exhibitionism into a more authentic life form.

I propose to refer to this as empowering exhibitionism, in the footsteps of Hille Koskela who coined this term some years ago. In Koskela (2004) she analysed visual representations characteristic of reality shows, mobile phones, and Internet webcams. She argued that subjectivity can be reaffirmed if people choose to play a more active role in the production of such images. A prime example of such empowering exhibitionism was the 'Jennicam' installed by Jennifer Ringley. I would argue that this term can be transferred to the online diaries that are the focus of this article. Bloggers, who usually reveal many details of their intimate lives, may be said to be engaged in empowering exhibitionism. I would argue that diaristic blogs have even more empowering potential than publicly visible webcams portraying people's lives. Besides online pictures and images of a life they can also expose various texts. Moreover, blogs may allow comments on entries, comments on comments, and so on. With that, one's public life becomes ever more intertwined with the public lives of others.

Koskela presents empowering exhibitionism as a monolithic concept. I think it is more useful to distinguish between several degrees of empowerment. Therefore, in the sequel I explore varieties of empowerment among bloggers. It is argued that the exhibitionism involved always amounts to an effort to create one's own synopticon, i.e., to be the director of one's own theatre performance, revolving around one's personal life. Furthermore, if exhibitionism is taken to extremes, it may affect panopticism as well by returning the gaze of surveillance and rendering it potentially meaningless.

\section{Public-private distinctions}

Blogs are vehicles of empowerment. But in what ways and to what extent is empowerment actually implemented? Bloggers have to draw for themselves the fine lines between public and private. How is this inherent tension being handled? If the metaphor of the synopticon is taken literally, these questions can equivalently be formulated as follows: Who is welcome in the blogging synopticon, and on what terms? What kind of 
intimacies are being put on the online stage by the director of the diary? While reflecting on the publicprivate divide, bloggers turn out to make one important distinction: between strangers in virtual life on the one hand, and people they know in 'real life' (relatives, friends, acquaintances, colleagues) on the other. Remarkably, bloggers worry much more about the latter than the former. To them, it is real life that may complicate blogging considerably.

The various forms of empowerment will be shown to revolve around two traditional notions of privacy (for the following, cf. the overview in Introna 1997). First the notion, as developed by Charles Fried, that privacy is a necessary prerequisite for developing intimate relationships. Relinquishing private information step by step builds up involvement and mutuality. The second conception involved - as developed by James Rachels - focuses on the efficient differentiation of levels of privacy as appropriate to a variety of social roles. Relational structures are simplified while not burdened with superfluous and possibly complicating information about the actors.

Not all bloggers have clear ideas about the matter, of course. As far as these have crystallized, however, basically three approaches to the distinction between public and private could be identified from the material at hand. ${ }^{2}$

\section{First approach to privacy}

In the first approach, bloggers welcome people from both virtual life (the unknowns) and real life (the people they know). All are admitted to their synopticon. However, they are worried about the feelings of the people they know from real life that appear in their blog. Correspondingly, their blogging has to proceed with some caution: details are omitted and identities concealed. Not just anything can be exposed.

There are several varieties of this concern. To begin with, bloggers may fear that their acquaintances might become offended or feel compromised. 'Miss Xombie', blogging since mid-2007, states this as follows:

I am constantly worried about backlash from family members, even though I've not written anything even remotely unflattering.

Disclaimer: If you know me in real life, or even think you know me, if I'm related to you, either by blood or by marriage, please don't take the words I place here personally.

\footnotetext{
${ }^{2}$ It cannot be ruled out, of course, that further research will uncover other approaches to the public-private distinction.
}

[...] If it is [about you], you will know I am referring to you, because I will have brought it up to you, someplace other than here.

(disclaimer on her blog, dated 13 January 2008, retrieved from http://missxombie.com/category/xombie)

Out of this concern, bloggers sometimes require known persons from real life to make themselves known. They want to know their audience from real life so they can adapt their entries accordingly. Athena warned her readers to think first:

If you know me personally [...], please consider whether or not you really want to read what I write. $[\ldots]$ some of the things I reveal may or may not be things you want to know. [...] I know the risk involved with everyone I've ever known possibly reading it. I'm fine with that. I just want to make sure you are too. [...] If you do make the choice to read, please drop me a line and let me know.

('disclaimer of sorts' on her blog, retrieved from http://www.lexxicon.net; now deleted, but quoted in Sorapure 2003, p. 11)

Another more unusual variety of this worry is that online diarists may feel uncomfortable about the fact that people they know read their intimacies, but not vice versa. As a result, the balance of intimacies between them and the people close to them might become disturbed. (S)he comes to feel that, in a curiously inverted sense, these lurkers intrude upon her/his privacy. Ariel Meadow Stallings, who has been keeping a blog called Electrolicious from the year 2000 onwards, expresses this concern perceptively:

If I know you in real life, and you read this blog, you really need to make the effort to communicate with me. [bold in original] For some strange reason I'm fine with people I don't know lurking in the sidelines, reading about this strange woman on the interweb [sic]. I don't know them, they don't know me. But if I know you in real life, your right to lurk is unequivocally revoked.

People I know lurking on Electrolicious contributes to this strange feeling that there are a lot of people in my "real life" who know me, but don't give me the opportunity to know them. [...]

If I know you, you read Electrolicious, and you don't communicate with me, you're committing a strange sort of emotional vampirism.

(post called One-Way Mirror, dated 25 October 2003; retrieved from http://electrolicious.com/ 2003/10/oneway_mirror)

In this first approach to privacy the whole world out there is always welcome, both anonymous and non- 
anonymous. The diaristic synopticon is declared open to all. Trust, as evidenced in the entrusting of intimacies, equally applies to all, as ex ante assumed trust - albeit that non-anonymous readers may have to fulfil the extra condition of notification in order to (continue to) earn this trust.

\section{Second approach to privacy}

A second, quite different approach to the tension between public and private is to try and exclude from one's blog known persons from real life. If you happen to know the blogger, you are refused entry to the synopticon. Explicit messages on the diary (under headings like 'please read', 'read first') warn relatives, friends, and acquaintances to stay away. If these want to continue reading the blog nevertheless, they should notify the author. So these bloggers explicitly entrust their intimacies only to anonymous strangers, to people who do not know them in real life (cf. several instances in Lejeune 2000, for example p. 326; McNeill 2003, pp. 37-39; Sorapure 2003, pp. 11-12).

Two examples may illustrate this approach. Trance, in her TranceJen journal, keeps her advice to readers very short: 'Think. If you know me in real life, you shouldn't be here' [bold in original] (retrieved from http://trancescrap.diaryland.com; now deleted, but quoted in Sorapure 2003, p. 11). Another more polite and more elaborate example is provided by the blog 'Life \& Times of a History PhD Student' (all quotations below from the entry called Please Read, dated 23 April 2007, retrieved from http:// lifexhistory.wordpress.com/about). Under the heading 'Please Read', the author informs her readers that

[...] it is certainly possible for people who know me to stumble upon this blog. If you do know me, either in real life, or through online correspondence and friendship via the blogosphere, please keep in mind that I would like to keep this blog as generally anonymous.

Subsequently, people who know her are urged not to mention her name, place of residence, or university affiliation when sending back comments on her blog, nor to pass on information from the blog to anyone else in the university. Moreover, 'if you do know me "in real life" [...], please do me the courtesy of asking to read my blog or refrain from reading my blog all together'. At the end, she warns that 'a violation of any of the above will at the very least lead me to delete your comments. I also reserve the right to block your comments in the future, though'. So this blog is preferably for anonymous visitors only (even pure Internet contacts are excluded), and nonanonymous visitors should explicitly ask for possible permission to read.

Such diarists, then, want to cordon off their virtual diary from their real life (or any other existing circle for that matter, whether real or virtual). Their anonymity, which facilitates the exposure of intimacies, should be guaranteed at all times. By introducing these rules the blogger seeks to protect his/her own privacy inside the blog's community. So paradoxically, this kind of blogging may at first sight look like an open invitation, but, in fact, intimacies are properly entrusted only to virtual, anonymous participants. Ex ante assumed trust is involved. People other than this, the 'non-strangers', are met with utter suspicion and - indeed - distrust. This distrust towards them is inferred from their known identities.

On reflection, this is not such an 'odd desire' as it might seem (to Sorapure at least: Sorapure 2003, p. 12). After all, many of us maintain a portfolio of memberships of a wide range of communities that often we do not want to intermingle. We may well feel that intimacies can be shared with our therapy group and when confessing in church, but not with our baseball team or our colleagues from work. Such reasoning corresponds with Rachels' conception of privacy, referred to above.

\section{Third approach to privacy}

A third and final approach to the tension between private and public is more radical: it seeks to abandon the distinction altogether (cf. discussion in Serfaty 2004, pp. 90-91). There is nothing to hide, anything of a personal nature can be exposed to anyone. In fact, the whole notion of privacy is declared obsolete. The diaristic synopticon is declared open to all, no permission to enter is required from anyone. Ex ante assumed trust towards people in cyberspace is fully re-established.

An early example of this radical stance is Tracy Lee. She started blogging in 1995, determined to include both texts about and erotic pictures of herself.

What would make my site different from the other journals out there already would be that I wouldn't hold anything back. Good times, bad, arguments, sex - whatever was happening in my life that I'd normally write about in my personal journal would go up on the website.

(interview from 2000; retrieved from http://www. diaryhistoryproject.com/recollections/1995_09_02. html) 
With a similar but more elaborate vision, Carolyn Burke started her online diary a year later.

I believed strongly in the power of good that results from free expression, free information exchange, and open and honest communication between people. [...] An online diary, a place that exposed private mental spaces to everyone's scrutiny seemed like a social obligation to me. I felt at the time that I could give back to society something important: a snapshot of what a person is like on the inside. This is something that we don't get access to in face to face, social society. Our intimacies are hidden, and speaking of them in public is taboo.

I questioned the privacy taboo. I disagreed with it. I exposed my private and intimate world to public awareness.

[...] I wanted everyone in the world to expose their inner lives to everyone else. Complete open honest people. What a great and ideal world would result. (interview from 2000; retrieved from http://www. diaryhistoryproject.com/recollections/1995_01_03. html)

A German blogger, Tobi, espouses the same vision in a 'petition' for eliminating the option of private weblogs (i.e., with restricted access) at Antville.org:

[...] a private weblog as such is a paradoxon.

Perhaps the most unambiguous difference with a diary: one does not put one's own diary on a heap of journals, books and manuscripts in a cafe, free for the taking.

[...] And aren't weblogs more like an antipode to the diary? The publication of what has been unjustly kept from the public sphere and not the falsifying self-expropriation of the private? The restoration of a public sphere where the diary belongs but does not end up any more? The retaking of the public sphere and not the sellingoff - no: the shrinking of the intimate sphere that has been violated anyway?

There is no such thing as private publicity.

OR:

There is no such thing as public privacy.

[my translation of this German post; last 2 English sentences in original]

(post dated 13 May 2003; retrieved from http:// tobi.antville.org/stories/380524/)

So, as an interesting aside, contrary to the usual interpretation that considers diaristic blogs to be the direct successor of classical diaries (e.g., Serfaty 2004), Tobi turns the relationship around and argues for the inherently public character of such blogs.
This third kind of exhibitionism can be seen to be more empowering than the first two approaches. Not only are such diaries a synopticon produced by the authors themselves, they also have the broader societal impact of being directed against the panopticist tendencies of our time. By practising total transparency, the societal gaze is returned. In the words of Koskela (2004): by confronting the regime of control and the regime of shame (as embedded in the concept of privacy), Big Brother surveillance is subverted and potentially rendered meaningless. ${ }^{3}$

This subversive character of 'extreme' blogging has not gone unnoticed in blogging circles. The link between total transparency and honesty on the one hand, and societal subversion on the other, is discussed by Miles Hochstein. He keeps a diary filled with text and images (going back to his youth), meant to 'document' his life in full.

In the 21 st century we are witness to "cam-girls" (and camguys? and autodocumenters?) who live their lives online, and to bloggers who report their daily activities and musings. The idea of not being hidden, or of breaking down the normal barriers to privacy, is in play. What they may share with this website is an interest in being rebelliously indifferent to observation. We are all engaged in resisting the idea that we are disempowered by being seen, or that we can only find empowerment by being private. Some of us even suspect that the need for privacy plays right into the dominance structures that are predicated upon one way observation. We are perhaps fighting the use of observation as a technique of power, by claiming the status of "being observed" as a way of empowering ourselves, and thus of dismantling the use of one way observation to dominate and shame and control. (preamble to his diary entitled Documented Life, available at http://documentedlife.com/log; preamble now deleted, but quoted in Serfaty 2004, p. 89$)^{4}$

As a corollary, the radical consequences of such 'extreme' empowering exhibitionism should be noted. For one thing, above I remarked that ex ante trust in visitors to the blog had been re-established. On closer

\footnotetext{
${ }^{3}$ This third kind of exhibitionism is actually the main focus of discussion in Koskela (2004). By distinguishing three approaches to the public-private distinction, I in fact propose a broader interpretation of empowering exhibitionism than Koskela.

${ }^{4}$ Immediately, of course, the question imposes itself whether Hochstein might possibly just be echoing some phrases from Koskela (2004)? Or is it the other way round? I have not been able to detect an answer to these questions.
} 
inspection, however, it is more accurate to say that assuming trust is no longer needed, while trust no longer applies. Those who plead for total transparency, ipso facto have nothing to lose. They do not feel vulnerable when exposing intimate details of their lives to the public gaze. Without vulnerability there is no perception of risk and blogging is no longer an act of implied trust. Connected to this, the exhibitionism involved changes in a subtle fashion. Exhibition of the details of one's life is no longer accompanied by shame, no inner resistance has to be overcome. In that sense, although we as onlookers may still feel ourselves to be voyeurs, the bloggers themselves are proper exhibitionists no longer.

\section{Blogging in practice}

Blogging about one's life may be a hard game to play. Whatever their conceptions of privacy, its practitioners have to face formidable obstacles. To begin with, virtual strangers may cause trouble. Bloggers may assume readers to be worthy of their intimacies - but not all of them conform to this assumption. Harassing and 'trolling' by complete strangers are common phenomena in these circles. In response to nasty comments, many bloggers have to use the delete options.

More generally, blogging codes of ethics are sometimes proposed to handle the matter. Let us for example have a look at the recent discussion that Tim O'Reilly initiated on his blog O'Reilly Radar, on 8 April 2007, about a code of conduct that should restore 'civility' in the blogosphere (see the report on http://radar.oreilly.com/archives/2007/04/draft_ bloggers_1.html). Its main clauses are that unacceptable content will not be posted but deleted, anonymous comments will be refused, and trolls will not be responded to - all at the discretion of the blog owner. This aroused a storm of comment, much of which carried the same nasty tone that the code was intended to filter out. Of course, all proposed measures of 'comment management' nibble at the edges of public access. 'Censorship' - towards the world outside at least - is re-entering the scene.

Secondly, people who populate one's real life may become a source of anguish and trouble. Whatever one's conception of privacy and associated synopticist regime chosen, problems are bound to arise. Colleagues and superiors from work may discover that they appear in diaries on the Net, and not be too happy about it. Ultimately, people may even get fired for it. Several incidents have been reported of bloggers losing their jobs for this reason (cf. for example the case of Heather Armstrong; see http://www.dooce.com).
Furthermore, one's friends and relatives may be embarrassed to figure openly in diaries, and react accordingly. Even someone like Carolyn Burke, mentioned above, who is a proponent of total transparency, felt compelled to stop blogging for a while for this reason:

Three years into my diary, I stopped writing publicly. There were troubles in my life that couldn't be placed online without serious repercussions. [...] When they resolved a year later, I began exposing my writings again. I truly regret hiding that way. I felt that I let my dream to be brutally open and honest down.

(interview from 2000; retrieved from http://wwww. diaryhistoryproject.com/recollections/1995_01_03. html)

Friends and relatives may also intrude in diaries, not so much while feeling embarrassed, but simply by commenting on the entries. This may shred the anonymity that the author imagined (s)he enjoyed. A case in point is Tracy Lee, who, like Carolyn Burke, initially believed in total transparency. After 2 years she had to concede that she was vulnerable after all, and decided to shut down her diary (reopening it later with restricted access only).

In the end my idea of being totally honest started to backfire as more and more people in my real life became aware of the journal. I didn't mind if friends read it, but I did mind when they read it and commented on it to me. When what anonymity I had in the journal that allowed me to be free and write unrestricted disappeared then it stopped being enjoyable and I shut it down.

(interview from 2000; retrieved from http://www. diaryhistoryproject.com/recollections/1995_09_02. html)

She also recalls how a total stranger approached her in a nightclub and told her that he had seen her naked. This was an additional reason to stop her public presence. Virtual strangers may unexpectedly turn up in real life too.

All this is to show that intimate blogging in the public gaze, whether in a more 'cautious' or in a more 'extreme' fashion, is not without its troubles. Notions of privacy, of the line between public and private, are being put to the test all the time. Virtual strangers may turn out to be nasty trolls, and people one knows from real life may be experienced as intruding in a variety of ways. As a result, bloggers may feel forced to reconsider their original conceptions of how much intimacy blogging in the open can bear. Henceforth their diaristic sites may become less publicized, inti- 
macies omitted from the entries, and/or technological measures taken to 'manage' one's privacy (censorship of comments, password restrictions on entry; cf. above). At any rate, living on the web will be most difficult for those who cherish the conception of total transparency and attendant invulnerability. The chances are that, after a while, they will feel forced to acknowledge that vulnerabilities are involved after all. They will then have to retrace their steps and at least adopt a more traditional notion of privacy.

\section{Conclusions}

Assuming, not inferring trust is an intriguing mechanism to generate trust. While discussions about it go back as far as Niklas Luhmann, it has only recently been put on the research agenda by a series of scholars, especially those studying the Internet. My main purpose has been to draw attention to diaristic blogging: most authors, their identity hardly concealed, expose the intimacies of their lives squarely to the public at large. I have argued that this voluntary exposure cannot be explained by the usual mechanism of inferring trustworthiness. Instead, authors simply assume that visitors to their blogs can be entrusted with their intimacies. And this gamble does indeed seem to pay off: many visitors do return respectful comments. How is this to be explained? It has been argued that authors, sitting safely behind their screens, proceed to trust a generalized other (one-to-many communication). It is up to the (chance) visitors whether or not they are amused or even enchanted by the blog's entries. If they are, they may feel bound to return sympathetic comments to their author; if they are not, they may feel bound, at any rate, to refrain from abuse. So in effect, the normative power of assuming trust is twofold.

At the same time, this phenomenon of blogging about one's life in (near) total transparency has been connected to current debates about our 'voyeur nation', our 'viewer society'. Voyeurism combined with exhibitionism are the defining characteristics of our current media experiences. They are to be interpreted as a 'perverted' reaction to the ever-increasing erosion of our privacy in this information society. It has been argued that blogging, by contrast, is a form of direct expression of the self, to be denoted as 'empowering exhibitionism'. The synopticon envisaged may be threefold: one open to all, in which accommodation of the sensitivities of known people from real life is the main source of concern; one that only welcomes virtual strangers, so known people from real life are preferably excluded; and one open to all, in which total transparency is the norm and concern for - anyone's - privacy is declared obsolete. In the last type of blog the gaze of surveillance is proudly resisted and returned; our panopticist society is targeted as well. As regards trust, a notable result of this interpretation of blogging as empowering exhibitionism is that online diarists turn out not always to assume trust indiscriminately. In the second type of synopticon, separated from real life, persons whom the blogger knows in real life are explicitly met with distrust from the very start - inferred this time from their real-life identities.

Finally, blogging has been shown to be a difficult life form on the Internet. In practice, not only anonymous trolls may disturb a blogger's community; known people from real life may also feel embarrassed and interfere accordingly, or simply shred whatever anonymity was left to the author. As a result, bloggers often feel forced to become less frank and less honest, to 'censor' incoming comments, and to reinstall password restrictions on entry. This is a dangerous development, while it may undermine the very assumption of generalized trust upon which the whole phenomenon of blogging is based.

\section{Open Access}

This article is distributed under the terms of the Creative Commons Attribution Noncommercial License which permits any noncommercial use, distribution, and reproduction in any medium, provided the original author(s) and source are credited.

\section{References}

All websites mentioned, in both text and references, were last visited on 1 February 2008.

A. Baier. Trust and Antitrust. Ethics, 96(2): 231-260, 1986.

A.C. Baier. Trusting People. Philosophical Perspectives, 6, Ethics: 137-153, 1992.

M. Bakardjieva and A. Feenberg. Involving the Virtual Subject. Ethics and Information Technology, 2: 233-240, 2000.

R. Blood. Weblogs: A History and Perspective. Rebecca's Pocket. Retrieved from http://www.rebeccablood.net/ essays/weblog_history.html, September 7, 2000.

C. Calvert, Voyeur Nation: Media, Privacy, and Peering in Modern Culture. Westview Press, Boulder, CO, 2000.

P.B. de Laat. Trusting Virtual Trust. Ethics and Information Technology, 7: 167-180, 2005.

N. Döring. Personal Home Pages on the Web: A Review of Research. Journal of Computer-Mediated Communication, 7(3), 2002. 
D. Gambetta. Can We Trust Trust?. In D. Gambetta, editors, Trust: Making and Breaking Cooperative Relations, pp. 213-237. Blackwell, Oxford, 1988.

S.C. Herring, L.A. Scheidt, S. Bonus and E. Wright. Bridging the Gap: A Genre Analysis of Weblogs, 2004. Retrieved from http://www.ics.uci.edu/ jpd/classes/ ics234cw04/herring.pdf.

L. Introna. Privacy and the Computer: Why We Need Privacy in the Information Society. Metaphilosophy, 28: 259-275, 1997.

S.L. Jarvenpaa and D.E. Leidner. Communication and Trust in Global Virtual Teams. Organization Science, 10(6): 791-815, 1999.

H. Koskela. Webcams, TV shows and Mobile Phones: Empowering Exhibitionism. Surveillance \& Society, CCTV Special, 2(2/3): 199-215, 2004.

S. Kozlov. Achieving Privacy in Hyper-Blogging Communities: Privacy Management for Ambient Intelligence, 2004. Retrieved from http://www.sics.se/privacy/wholes2004/ papers/kozlov.pdf.

Ph. Lejeune. “Cher Ecran...”': Journal personnel, ordinateur, Internet. Editions du Seuil, Paris, 2000.

N. Luhmann. Vertrauen: Ein Mechanismus der Reduktion sozialer Komplexität. 1968. 4th ed. Lucius \& Lucius, Stuttgart, 2000. English translation in N. Luhmann. Trust and Power. John Wiley, Chicester, 1979.

Th. Mathiesen. The Viewer Society: Michel Foucault's 'Panopticon' Revisited. Theoretical Criminology, 1(2): 215-234, 1997.
L. McNeill. Teaching an Old Genre New Tricks: The Diary on the Internet. Biography, 26(1), Special Issue, Online Lives: 24-47, Winter 2003.

D. Meyerson, K.E. Weick and R.M. Kramer. Swift Trust and Contemporary Groups. In R.M. Kramer and T.R. Tyler, editors, Trust in Organizations: Frontiers of Theory and Research, pp. 166-195. Sage, Thousand Oaks, CA, 1996.

C.R. Miller and D. Sheperd. Blogging as Social Action: A Genre Analysis of the Weblog. 2004. Retrieved from http://blog.lib.umn.edu/blogosphere/blogging_as_social_ action_a_genre_analysis_of_the_weblog.html.

Ph. Pettit. The Cunning of Trust. Philosophy and Public Affairs, 24(3): 202-225, 1995.

Ph. Pettit. Trust, Reliance and the Internet. Analyse und Kritik, 26: 108-121, 2004.

J. Schmidt, Weblogs: Eine kommunikationssoziologische Studie. UVK Verlag, Konstanz, 2006.

V. Serfaty, The Mirror and the Veil: An Overview of American Online Diaries and Blogs. Rodopi, Amsterdam/ New York, 2004.

M. Sorapure. Screening Moments, Scrolling Lives: Diary Writing on the Web. Biography, 26(1), Special Issue, Online Lives: 1-23, Winter 2003.

P. Wallace, The Psychology of the Internet. Cambridge University Press, Cambridge, 1999.

J. Weckert. Trust in Cyberspace. In R.J. Cavalier, editor, The Impact of the Internet on Our Moral Lives, pp. 95-117. State University of New York Press, Albany, NY, 2005. 